\title{
Fostering a sense of belonging: supporting the early formation of student identity as successful learners in higher education
}

\section{Sarah Parkes}

Newman University, UK

\section{Abstract}

Since the Widening Participation (WP) policy of the New Labour Government (1997-2010) and the increased market-like environment created by raised tuition fees, institutions are increasingly focusing significant effort on enhancing the student experience in order both to retain existing students as well as competitively market themselves to prospective students (Brown, 2011; Department for Business, Innovation and Skills, 2011; Thomas, 2012). Pre-entry activities that include Information, Advice and Guidance (IAG), supporting social and academic integration, managing student expectations and encouraging the development of appropriate academic study skills (Gorard et al., 2006; Crabtree et al., 2007) have thus been utilised to engage new learners in the experience of Higher Education (HE), with the potential to influence their progression and retention once onprogramme (Thomas, 2002; 2011; Yorke and Thomas, 2003; Thomas and Quinn, 2006; Thomas and Jamieson Ball, 2011). Thomas (2011, p.45) suggests that evidence does indeed indicate that such pre-entry interventions ought to influence retention and progression yet it is still not clear how such interventions affect a student's experience of HE.

Drawn from interviews conducted in 2012, this paper discusses the experiences of students participating in HEADstart; a two week pre-entry blended learning course at Newman University, Birmingham. Using notions of belonging, this thematic analysis explores the extent to which participation supports the early formation of a sense of belonging in $\mathrm{HE}$, which is a key element to successful student progression and success (Thomas, 2012).

Keywords: Pre-entry, Expectations, Transition, Integration, Belonging, Retention 


\section{Introduction}

Work previously associated with the Widening Participation policy of the New Labour Government (1997-2010) sought to improve access and participation of groups who were under-represented in Higher Education (HE) (Higher Education Funding Council for England - HEFCE, 2004). Pre-entry activities that worked to encourage participants to develop aspirations to study within HE were one of the ways in which access to university was thus promoted. However, how such activity continues to influence students' experiences in the first year of their degree and beyond has been largely ignored (Thomas, 2011, p.45). This paper adds to the discussion and debate by asserting that participation in HEADstart, a pre-entry blended learning course at Newman University, positively affects a student's subsequent experience of $\mathrm{HE}$, and thus their commitment to continuation, through fostering an early sense of belonging. This assertion is supported by data gathered as part of an endogenous study conducted in 2012 by the academic staff responsible for delivering the course.

After brief discussion of the importance of pre-entry activities in supporting retention, followed by subsequent commentary on research methodology, this paper explores the extent to which participation in HEADstart affects the experiences of students involved through thematic analysis of interviews conducted with past participants. This is interpreted with regard to the extent that HEADstart fosters a sense of belonging in students through supporting the early formation of identity as a successful learner in HE. Specifically, this considers how participation shapes a student's expectations of HE and the extent to which HEADstart assists with developing basic academic skills, such as independent learning and time management, increasing awareness in students of the greater need to organise their own time and take responsibility for their learning. The effect of participation on student confidence, and knowledge to ask for help from peers, academic staff and professional service staff, is also explored.

\section{What is HEADstart?}

HEADstart was initially designed as a 14 day blended learning pre-entry course for potential students who did not possess the necessary UCAS tariff or prior experience to meet the entry requirements for their desired program. Previously such students were 
accepted onto their programme of study via a Certificate of HE (CertHE), with university transition supported through a generic study skills module to be completed in tandem with their subject specific level four modules. However, feedback from 0506-0809 cohorts indicated that students would prefer activities before they started their course. They believed that the extra generic on-programme module contributed to a greater workload and put too much pressure on them during a time of anxiety and change. Indeed, staff reported that their students were overwhelmed by the demands of their subject and the additional work associated with the CertHE.

Since the pilot in 2009, HEADstart has evolved into a course which is no longer explicitly for such students, but offered to all new undergraduates. Following Dodgson and Bolam's (2002, p.24) assertion that the summer period is a useful timeframe for conducting activities that prepare students for HE, HEADstart delivery commences during the two weeks prior to Fresher's Week. Aligning the course so closely to the start of the academic year enables students to access all the institutional systems they would expect to interact with once enrolled on-programme, whilst providing the opportunity to make friends with other students who they are most likely to be studying alongside.

With similar aims to other pre-entry activities (see Walker, 1999; Blicharski and Allardice, 2000; Cook, 2009; Hatt et al., 2009, p.339), one of the ways HEADstart affects the subsequent HE experience of participants is by providing early exposure to the skills needed to cope with the demands of HE. Where HEADstart differs from other work in the sector is in its construction: as a blended learning course, students interact via workshops on campus and online 'e-tivities'. These are underpinned by constructivist theories whereby '...learners create knowledge as they attempt to understand their experiences' (Driscoll, 2000, p.376) this can be seen through continuing interactions within the discussion forum and reflection in their personal learning journals. 'E-tivities' are designed to encourage a reflective approach to learning, generating 'an ongoing set of attitudes' (Vaill, 1996, p.42) to help students navigate the demands of university life and increase their digital residency (White and Le Corno, 2011) once on-programme. This links to Siemens' notion of 'connectivism' (2004) whereby, in the ever increasing world of new knowledge, learners must be prepared to learn how to learn: it is just as important to 'know-why and how' learning is facilitated before the 'know-what' is learnt. 
During the course students independently complete online tasks such as entries into their journal, to include reflections on their previous experience and future aspirations, alongside interactive study skills tasks. Furthermore, they are taken through the process of preparing subject related 'practice assignments' which are completed and submitted on the final day. Throughout the course, members of the Senior Academic Support Team (SAST) (see Parkes et al., 2013) work with a group of students whose degree subject is aligned to their own. Utilising the SAST team in this way introduces institutional support mechanisms to the students early on. SAST comment on student reflections detailed within the personal learning journal; HEADstart discussion boards; and provide feedback on the 'practice assessments' that are completed at the end of the course. HEADstart students are also supported over the two weeks by HEADstart mentors: mentors are students who have previously participated and successfully progressed into their second or third year of study.

\section{Student retention: engagement, belonging and identity and pre-entry activity}

The reasons why students continue to study or leave university early are multifaceted. They are attributable to both the characteristics of the student, along with the pedagogy and processes employed within the institution. Historically, retention has been seen as only attributable to entry characteristics such as family, class, race, academic aptitude and economic status alongside the level of student involvement in social and academic activities (Goodenow and Grady, 1993, p.60; Walker et al., 2004, p.53; Berger and Lyon, 2005, p.20). However, it has since been accepted that student retention is part of a much more complex social and cultural picture (Quinn, 2004, p.59-63; Walker, 2004, p.45) and though many of the aforementioned student characteristics play a part, student persistence is further influenced by the interaction between individuals, institutions and wider society. Indeed, 'institutional habitus' (McDonough, (1996) and Reay et al. (2001), cited Thomas, 2002, p.431) affects student retention through '...the impact of a cultural group or social class on an individual's behaviour as it is mediated through an organisation' in turn, determining '...the way in which difference is dealt with, and thus the way students encountering difference for the first time react' (Thomas, 2002, p.439). In this way then, institutional structures and attributes could be seen as perpetuating the dominant cultures in society through pedagogy and process that socialise and reinforce 
societal status (Thomas, 2002, p.431; Quinn, 2004, p.58). Thus organisational attributes of institutions that go on to influence student persistence should be considered when discussing student retention (Berger and Lyon, 2005; Kuh et al., 2005; Tinto, 2006; James et al., 2010) rather than longing for a more homogenous student body (Thomas and May, 2011, p.12).

Key to student retention is the successful generation of a sense of belonging within students (Osterman, 2000; Krause, 2011; Thomas, 2012). This can be defined as a students' sense of being accepted, valued, included, and encouraged by others in the academic setting and involves supporting and respecting the personal autonomy of the student as an individual (Goodenow, 1993, p.25). This sense of belonging is fostered during interactions within the social, academic and professional services spheres of a student's experience. The success of such activity is underpinned by ensuring that student and staff capacity is built and supported across the student lifecycle: from pre-entry to employment.

The 'Student Engagement to Improve Student Retention and Success' model (Diagram One) encompasses a set of key characteristics, underpinning principles and wider institutional culture that intend to foster student belonging (Thomas, 2012). This sense of student belonging is achieved through: '... supportive peer relations; meaningful interaction between staff and students; developing knowledge, confidence and identity as successful HE learners and providing a HE experience relevant to students' interests and future goals'. The model reflects findings from a UK national longitudinal study that suggest activities across all institutional domains: the academic, social and professional service spheres (Thomas and May, 2011) foster student engagement that promotes student retention and success. 


\section{Diagram One. Final version of Student Engagement to Improve Student Retention and Success (Thomas, 2012).}

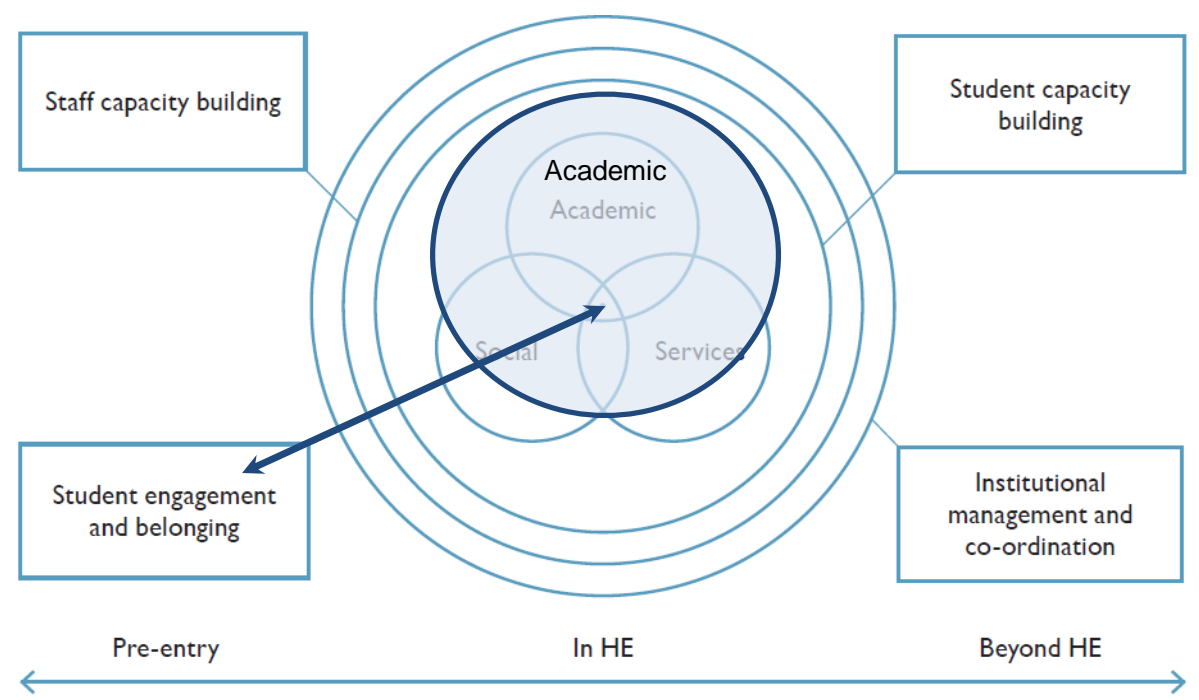

Following the logic of the model, activity located at the pre-entry stage of the student lifecycle that builds staff and student capacity should support belonging and thus retention. Indeed, issues identified within the literature as contributing to student attrition, such as poor preparation for HE and lack of social/academic integration (Connor and Dawson (2001), cited Dodgson and Bolam, 2002, p.17; Doherty et al (2007)., cited Thomas, 2011, p.239; Yorke and Longden, 2008, p.238) highlights the importance of preparation and admission; induction and transition support; social engagement and student support (Thomas, 2011).

Associated with academic preparedness and support prior to entry, Thomas (2011, p.242) with Harvey and Drew (2006) propose that a failure to adjust and integrate within a HE context, perhaps borne from a mismatch between expectation and actual experience (Quinn et al., 2005; Gorard et al., 2006; Crabtree et al., 2007), all contribute to student withdrawal (Mclinden, 2003, p.5). Thomas (2011, p.239) and Jones (2008) both indicate that insufficient academic experience can be linked to student non-completion. This is perhaps demonstrated most succinctly by Yorke and Longden (2008, p.23-25) who state that students with no prior knowledge and/or experience of HE indicated, more often than their better-informed peers, that difficulties in coping with the academic demand were influential in their departure from their institution, and implied their withdrawal was due to a difficulty involving social integration with other students. 
Insofar as preparation for HE extends, Tinto (2006, p.7) discusses the merits of contextualised study skills courses as a way to potentially provide an experiential learning experience that '...constructs experience in a particular way, as something from which knowledge can be derived...through observation and reflection' (Usher and Soloman, (1999), cited Moon, 2004, p.104). Moreover, Thomas (2011, p.238) asserts that it is reasonable to expect that these courses could contribute to improving preparation for $\mathrm{HE}$, promoting commitment in the student to their studies and resulting in a satisfactory academic experience.

One example of such a pre-entry skills course is the longitudinal 'Flying Start' project at the University of Central Lancaster (UCLan) that focuses on developing the emotional and social intelligence of participants. By working with participants to develop these skills, the course encourages student progression and success, promoting better social integration and generating an ability in students to seek help or support when required (Engelberg and Sjoberg (2004) and Gohm et al. (2005), cited Cook, 2009). Cook (2009) asserts that on average $80 \%$ of participants have no parental experience of $\mathrm{HE}$ and that retention of 'Flying Start' students is twice as high as that of UCLan as a whole.

Walker (1999) and Walker et al. (2004) detail a further pre-entry activity; the 'Top Up' programme run by the University of Glasgow. This programme promotes academic preparedness in participants through activities designed to develop critical thinking; study skills and highlight the notion of deep and surface learning. 'Top Up' participants involved in focus groups believed that involvement in the programme had enhanced their university experience by providing the opportunity to practice academic tasks, familiarise themselves with the university campus and systems whilst developing greater confidence through selfreflection (Walker et al., 2004, p.54). By combining the findings from the focus groups with progression rates, the authors assert that the intervention positively affected student progression by promoting academic integration.

Blicharski and Allardice (2000) discuss pre-entry interventions available at the University of Dundee:

ACCESS; a 10 week programme that closely mirrors a standard undergraduate first year and aims to embed participants into full-time university support structures through an intensive educational experience. 
ASPIRE; a four week version of the ACCESS programme for participants who are closer to the entry levels for university and identified through their UCAS application.

Both courses aim to develop academic skills, confidence and self-esteem. Blicharski (1999), (cited Thomas, 2011, p.245) reports that participants appeared '...no more vulnerable to drop out than any other cohort of undergraduate students'.

\section{The research}

\section{Purpose}

The purpose of this small scale endogenous study was to understand the extent that participation in HEADstart goes on to affect the experiences of students and their subsequent progression and success in higher education and was, to a small degree, evaluative. The study was underpinned by three questions:

(i) How does participating in a pre-entry initiative shape a student's expectations of HE?

(ii) To what extent does a pre-entry intervention begin to develop basic HE academic skills?

(iii) How does participation in a pre-entry programme affect students' confidence and knowledge in terms of asking for help from peers, academic staff and professional service staff?

It is clear that establishing a causal relationship between participation in an intervention and student decision making regarding persistence would, as Longden (2006, p.176) agrees, '... present formidable methodological difficulties'. Using a non-probability sampling technique, this research was therefore situated within an interpretivist paradigm to acknowledge the complex relationship between people's attitudes and their behaviour. Student perspectives on their experiences of HEADstart were collected through semistructured interviews which were used to empower the interviewees by giving them time and freedom to express their views. This meant that ideas could be followed up, answers probed and motives and feelings investigated (Bell, 2005, p.157). 
As the researcher was the academic running HEADstart, discussion relating to the 'insiderness' of the study occurred during the research ethics approval process. It was recognised here that detachment from the subject matter could potentially pose difficulty, and thus the study did not propose to look for ' ... validity in any external or objective sense', though an open and critical attitude to practice and interpretation was maintained throughout. Moreover, the research reported here openly acknowledges that it took place within its own context and is inseparable from the world within which it exists (Trochim, 2006). Indeed, during thematic analysis of the interview transcriptions a process of exploration and elimination of interpretations took place. This was based on a reflective interaction with the 'preferences and methodological assumptions' present (Hart, 2005). Research ethics approval was granted in March 2012.

\section{HEADstart participants and research sample}

The numbers of HEADstart participants, between 2009-2012, are detailed in Table One.

Table One. HEADstart participation by year, gender and age.

\begin{tabular}{|c|c|c|c|c|c|c|c|}
\hline Year/cohort & Number & Male & Female & $\mathbf{1 8 - 2 1}$ & $\mathbf{2 2 - 3 5}$ & $\mathbf{3 6 - 5 0}$ & $\mathbf{5 1 +}$ \\
\hline $09 / 10$ & 30 & 15 & 15 & 18 & 9 & 2 & 1 \\
\hline $10 / 11$ & 55 & 14 & 41 & 28 & 21 & 5 & 1 \\
\hline $11 / 12$ & 33 & 9 & 24 & 13 & 11 & 8 & 1 \\
\hline Total & $\mathbf{1 1 8}$ & $\mathbf{3 8}$ & $\mathbf{8 0}$ & $\mathbf{5 9}$ & $\mathbf{4 1}$ & $\mathbf{1 5}$ & $\mathbf{3}$ \\
\hline
\end{tabular}

Students were invited to participate in the semi-structured interviews by email, using both institutional and personal addresses. Their contact details were taken from a database compiled as part of the registration process for HEADstart thus, all participants selfselected to be interviewed. 118 past participants were invited to take part with twenty students taking up the invitation. Due to time constraints, 15 out of 20 students participated in interviews, taking place over April and May 2012. The distribution of interview participation across the three cohorts is detailed in Table Two. 
Table Two. HEADstart interview participants by year, gender and age.

\begin{tabular}{|c|c|c|c|c|c|c|c|}
\hline Year/Cohort & Number & Male & Female & $\mathbf{1 8 - 2 1}$ & $\mathbf{2 2 - 3 5}$ & $\mathbf{3 6 - 5 0}$ & $\mathbf{5 1 +}$ \\
\hline $09 / 10$ & 5 & 1 & 4 & 0 & 2 & 2 & 1 \\
\hline $10 / 11$ & 2 & 0 & 2 & 0 & 2 & 0 & 0 \\
\hline $11 / 12$ & 8 & 2 & 6 & 3 & 1 & 3 & 1 \\
\hline Total & $\mathbf{1 5}$ & $\mathbf{3}$ & $\mathbf{1 2}$ & $\mathbf{3}$ & $\mathbf{5}$ & $\mathbf{5}$ & $\mathbf{2}$ \\
\hline
\end{tabular}

Within the total HEADstart population, the highest proportion of participants were between the age ranges of 18-21 and 22-35 years old respectively (see Table One): a pattern not repeated within the HEADstart sample where the most represented age range fell equally between 22-35 and 36-50 years old (see Table Two).

Participant numbers in HEADstart were similar for both 09/10 and 11/12 groups. However, most of the interviewees came from the $11 / 12$ cohort, perhaps a result of the course being relatively fresh in their minds. The difference in interview take up between these two cohorts may also have been affected by the timing of the interview request as this was made when third year students were most likely pre-occupied with completing their dissertations. Third year participants too, might be presented with difficulties in remembering the course and thus answering questions about it. Interestingly, there were only two participants from the 10/11 cohort; the largest of the three cohorts. The reason for this is unexplained though it may well be that informants might have been more willing to bare their souls to a detached outsider than to someone so intimately bound up with the life of the institution and so enmeshed in its power relations (Dimmock (2005), cited Mercer, 2007, p 7).

\section{The research findings}

Interviewees across all cohorts and ages were overwhelmingly positive about HEADstart though some expressed difficulty in articulating what it was about it that they felt was beneficial. However, despite such difficulties, it emerged that HEADstart promoted a sense of belonging as a learner in HE through: 
- Providing familiarisation with the campus, study environment and Newman University systems.

- Helping students feel motivated in their studies.

- Beginning to build peer to peer and staff relationships.

- Introducing the skills needed for successful study in HE.

- Exposing the existing attitudes participants had towards HE and encouraging the development of realistic expectations.

\section{Expectations of HE}

Gorard et al. (2006), Harvey and Drew (2006), Crabtree et al. (2007) and Thomas (2011) identified that a mismatch between expectation and actual experience in $\mathrm{HE}$ can negatively influence student continuation. The interviews across all cohorts indicated that HEADstart helped students to develop realistic expectations of HE. Leigh (lines 239-240) says that his '... pre-conceived ideas' of HE were blown out of the water during HEADstart and Lauren (lines 97-100) agrees that having the opportunity to 'practice' being at university was helpful:

...it was quite nice to be given a little bit of a taster...this is how to write academically, this is what a presentation is...because it is nervewracking.

We can therefore describe HEADstart as an experiential learning experience where the materials of learning are the direct experiences (Moon, 2004, p.122) that influence expectations. Thus, HEADstart generates an early sense of belonging by providing an opportunity for participants to be actively involved in coordinating and aligning their energy and power towards activities that affect their world.

\section{Motivation}

Increased motivation was reported by participants mainly from the $09 / 10$ cohort, yet is not a theme explicitly identified within the literature. Emma (line 79) says HEADstart helped her regain her '... old competitive spirit' whilst Vanessa felt that although she didn't '...know 
how [she was] going to do [it]', after completing HEADstart she was determined to get her studies done. Indeed, she '...stuck to it and did all that [she] needed to do' (line 206). For Vanessa, a student who had been undecided about university for years (lines 15-18; 61), HEADstart provided an initial spark that fostered a sense of belonging to begin development of her identity as a HE learner.

\section{Campus familiarisation, study environment and Newman University systems}

Similar to findings by Walker et al. (2004), all cohorts and ages commented on how HEADstart affects participant expectations of HE through providing the opportunity to experience the campus and university systems. Leigh (lines 78-79) and Lauren (lines 137139) discuss this in practical terms: for Leigh it was about ' ...just learning the basics [of]...how to use the computers' with Lauren agreeing that HEADstart provided familiarisation so that '....when you [came] back to start your degree....it's not quite as daunting'. Thus, as HEADstart participants become more comfortable in the physical HE environment, they begin to imagine their future selves as successful students.

\section{Academic skills development}

Through early exposure to academic conventions, students repeatedly reported increased confidence within essay writing, planning, referencing, presentation, collaborative working and time management. Though difficult to express at times, all interviewees commented that the course did 'something' that helped them with their academic work once onprogramme:

Even though it's taken 8 months...now I can see the connection there. (Joe, lines 165-175)

Referencing was highlighted as a particular skill that was acquired and developed through participation in HEADstart, as described by Abby (lines 131-135) upon discussing the HEADstart practice assignment: 
When I was doing the assignment for HEADstart I was like 'OK, I've thought of a point there, I need to reference' so... it was always there in my mind... if I hadn't gone on [HEADstart] l'd have been like 'whatever'.

Many asserted that the subject specific mini-assignments, and the support offered prior to compiling them, contributed to the development of their academic writing skills. Sarrah (lines 57-59) describes the academic writing classes as illustrating 'the jump from A-level writing to degree writing'. Ayshea (lines 54-56) comments positively on the introduction to collaborative work HEADstart provided '... because at A level we didn't do those....it kind of throws you into what you have to do, the different ways of putting it across really.'

Vicki (lines 200-212) says the collaborative tasks encouraged a period of self-reflection when things didn't go to plan. She asserts that as a student, you '... have to work with people you don't like... so if I do: how am I gonna work with them? How am I gonna challenge it? What do I need to do?'. Similarly the timetable of HEADstart, as described by Cassandra, highlighted the need for reflection on effective time management skills:

Interviewer: How does that reflect what your experience has been like on your course?

Cassandra: Independent learning: it's like the work is there for you to do, again it's up to you, like the pace that you want to go and again, you have to know how to manage your time in it (lines 113-114)

Thomas (2012, p.7) talks about how student belonging is generated through ensuring that the '...HE experience [is] relevant to students' interests and future goals', thus an important element for pre-entry interventions must be to ensure that the participants are involved in skills development activities that are relevant to their degree. By providing practical tasks aligned to the student's subject of study, engagement and thus belonging is promoted. This is contextualised within the HEADstart experience through subject alignment whereby students are offered '...support and respect for personal autonomy' (Goodenow, 1993, p.25) in a bid to generate a sense of belonging. 


\section{Increased confidence}

Both Walker et al. (2004) and Blicharski (1999, cited Thomas, 2011) reported that participants in their respective interventions were well prepared for $\mathrm{HE}$ through activities designed to build confidence and raise self-esteem. Equally, HEADstart interviewees from all cohorts reported that a sense of increased confidence prevailed after completion of the course. Joe (lines 194-196) believed HEADstart helped him overcome his '....initial nerves about...going to university... [as he] had two weeks to sort of find [his] feet'. Interestingly, interviewees discuss the establishment of a self-perceived increase in confidence during a relatively short period of time. Sarrah (line 198) asserts that she '...was able to pass on... knowledge' which Abby (line 104) describes as being given the 'upper hand'. This sense of 'knowing' was further elaborated by Kevin (lines 176-181):

I remember my first year presentation...my group was panicking about it...I was like: listen, I learnt this before...so...I felt more confident...I was able to tell them 'this is how we do it'.

The interviewees reported generally that HEADstart enabled them to begin to develop effective study skills, though a few participants implied that they initially felt inadequate, as Dawn describes (lines 140-149):

You almost feel like a failure before you start...it's almost saying to somebody that whatever you've done before is no good...but then...you feel a bit more confident as you go through them.

Whilst Dawn does state she got through it and came out feeling confident, this could potentially have amplified an imbalance of power where participants struggle to negotiate meaning thus disempowering them.

\section{Confidence and knowledge in students to ask for help from peers, academic staff and professional service staff}

Across the majority of the interviewees, HEADstart is seen as helping to build peer to peer and staff relationships. This could be interpreted as promoting a sense of belonging as a learner in HE. 


\section{Staff familiarisation}

Thomas and May (2011) and Thomas (2012) assert the importance of developing the capacity of students to engage effectively in their HE experiences across all spheres of institutional activity, including engaging in support with staff. Interview transcriptions highlight the sense of approachability participants felt towards members of professional staff, because they 'already knew a few faces of the tutors' (Dawn, line 131), familiarisation that was fostered during workshops in HEADstart. Sarrah (lines 164-167) echoes this when she talks of the library liaison officers she met on HEADstart: '.. I was able to just go to him... because I knew he was on the HEADstart and I knew his kind of job'. Indeed, the whole notion that you could ask for support at university was something all interview participants felt HEADstart had introduced them to, as Abby (lines 91-93) concludes '... if I'd have been just at uni starting I wouldn't... have done the asking and stuff'. The experience of participants was that HEADstart had a positive effect on their confidence and knowledge to ask for help from peers, academic staff and professional service staff.

\section{Building peer to peer relationships}

Thomas and May (2011) tell us that engagement in the social sphere of activity can foster a sense of belonging when integrated into the academic sphere. The importance of peer to peer relationships within the academic sphere can be most explicitly seen in Vicki's response (lines 129; 195-197), as she describes meeting a fellow student with whom she had to work on a presentation during HEADstart:

Maddy is still my mate now $[\ldots]$ I really enjoyed that, going to meet Maddy at a university library; never met this guy before...then we were getting together and getting this work done and it was really good!

Emma (line 316-319) also talks about the importance of interacting with others within the 'settling in process' (Walker, 1999, p.13; Quinn et al., 2005, p.20) and explains that HEADstart enabled her to have someone to talk and chat to. This resonates with Sarrah (lines 51-54), Pauline (lines 67-68) and Dawn (lines 131-136) who agree that HEADstart enabled them to make great friends, even with '... other students from other different courses' (Dawn, lines 131-136). 


\section{Concluding remarks}

This paper is underpinned by the notion that Higher Education Institutions should focus on what is within their power to influence with regard to promoting student retention and success, rather than wishing for increased homogeneity within the student body. Specifically, the discussions here surrounding HEADstart at Newman University explored how participation in pre-entry activity can positively affect a student's subsequent experience of $\mathrm{HE}$ through fostering an early sense of belonging, a key factor in successful student progression and success (Thomas, 2012).

Interviews conducted with participants on HEADstart have echoed the findings of Walker (1999) and Walker et al. (2004) which reported that participation had positively affected the student's experience of HE, aligning their expectations with the realities of study and allowing participants to become acquainted with the physical, social and academic study environments. Specifically for HEADstart, interviewees discussed how the course promoted a sense of belonging as a learner in HE through; providing familiarisation with the campus and study environment and Newman University systems; helping students feel motivated in their studies; beginning to build peer to peer and staff relationships and introducing the skills needed for successful study in HE. The experience exposed the existing attitudes participants had towards HE and encouraged the development of realistic expectations, consequently supporting the early formation of identity in students as successful learners in HE.

A limitation to this study is in triangulating the interview themes against retention and progression data. Initial investigations conducted into the retention and success rates of HEADstart students, compared to non-participants from the same programme (see Parkes, 2012), suggested that those participating in HEADstart were retained in HE at the same or better rate than non-participants. However, these investigations only looked at retention and progression after the first two years of study and did not look at student characteristics such as gender, class, race or disability. It would therefore be interesting to complement the findings reported here with a longitudinal analysis of retention, progression and success for HEADstart participants against non-participants by such characteristics and perhaps course type. Despite these limitations, this small scale study has not only increased understanding into how pre-entry activity, such as HEADstart, can 
positively affect a student's subsequent HE experience, but has also influenced institutional direction at the university during a time of key change.

Since 2012/13, these research findings have underpinned an institutional Academic Practice Fellowship into 'Induction and Transition'. The fellowship investigated the extent to which student belonging is nurtured through student-centred learning, teaching and assessment (which are offered through mainstream activities in the academic curriculum during the first year and during the first semester at each subsequent level of study). The conclusions from the fellowship inspired the development of fundamental modules that formed part of an institutional move to a 20 credit modular structure across which subject-based scholarship, study skills and independent learning are developed, particularly through reflective assessment.

\section{References}

Bell, J. (2005) Doing your research project. Maidenhead: Open University Press.

Berger, J.B. and Lyon, S. (2005) 'Past to present', in Seidman, A. (ed.) College student retention: formula for student success. Westport, USA: American Council on Education and Praeger Publishers, pp. 1-29.

Blicharski, J. and Allardice, M. (2000) 'Tracking students progression: learning their lessons', Widening Participation and Lifelong Learning, 2(3), pp. 32-37.

Brown, R. (2011) 'Markets rule, OK?', The Coalition Government's Higher Education reforms in context: Oxford lecture 14 November 2011. Available at: www.education.ox.ac.uk/wordpress/wp-content/uploads/2010/07/OXFORDLECTURE-14-NOVEMBER-2011.docx (Accessed: 17 February 2013)

Cook, V. (2009) 'Still flying ten years on!', Towards a New Agenda for Lifelong Learning: Access, Diversity and Participation: FACE Conference 2009. Staffordshire University, Staffordshire 1-3 July. Available at: http://www.f-a-c-e.org.uk/conferenceand-events/face-2009-conference.htm (Accessed: 3 November 2009). 
Crabtree, H., Roberts, C. and Tyler, C. (2007) Understanding the problems of transition into higher education. Available at:

http://www.ece.salford.ac.uk/proceedings/papers/35 07.pdf (Accessed: 5 November 2008).

Department for Business, Innovation and Skills (2011) Students at the heart of the system. London: Department for Business, Innovation and Skills.

Dodgson, R. and Bolam, H. (2002) Student retention, support and widening participation in the north east of England. Sunderland: Universities for the North East.

Driscoll, M. (2000) Psychology of learning for instruction. Needham Heights, MA: Allyn and Bacon.

Goodenow, C. (1993) 'Classroom belonging among early adolescent students: relationships to motivation and achievement', Journal of Early Adolescence, 13(1), pp. 21-43.

Goodenow, C. and Grady, K. (1993) 'The Relationship of School Belonging and Friends' Values to Academic Motivation Among Urban Adolescent Students', The Journal of Experimental Education, 62 (1), p 60-71.

Gorard S., Smith, E., May, H., Thomas, L., Adnett, N. and Slack, K. (2006) Review of widening participation research: addressing the barriers to participation in higher education. Available at: http://www.hefce.ac.uk/pubs/rdreports/2006/rd13 06/ (Accessed: 11 September 2008).

Hart, C. (2005) Doing your Masters dissertation, London: Sage

Harvey, L. and Drew, S. (2006) The first-year experience: briefing paper on integration. Higher Education Academy. Available at: http://www.heacademy.ac.uk/assets/documents/archive/first year experience briefi ng for policy makers and practitioners.pdf (Accessed: 1 January 2012). 
Hatt, S., Baxter, A. and Tate, J. (2009) 'It was definitely a turning point!' A review of Aimhigher summer schools in the south west of England', Journal of Further and Higher Education, 33(4), pp. 333-346.

Higher Education Funding Council for England, (2004), Aimhigher: Guidance notes for integration. H. 2004/8. Bristol: HEFCE.

James, R., Krause, K. and Jennings, C. (2010) The first year experience in Australian universities: Findings from 1994-2009. Available at: www.cshe.unimelb.edu.au/research/FYE Report 1994 to 2009.pdf. (Accessed: 5 December 2011).

Jones, R. (2008) Student retention and success: a synthesis of research. Higher Education Academy. Available at: http://www.heacademy.ac.uk/resources/detail/inclusion/wprs/WPRS retention synt hesis (Accessed: 8 November 2009).

Krause, K. (2011) 'Transforming the learning experience to engage students', in Thomas, L. and Tight, M. (eds.) Institutional transformation to engage a diverse student body. Bingley: Emerald, pp. 199-212.

Kuh, G.D., Kinzie, J., Schuh, J.H., and Whitt, E.J. (2005) Student success in college: creating conditions that matter. San Francisco: Jossey-Bass.

Longden, B. (2006) 'An institutional response to changing student expectations and their impact on retention rates', Journal of Higher Education Policy and Management, 28(2), pp. 173-187.

Mclinden, M. (2003) 'Retention: developing and implementing pre-entry, induction and ongoing retention tactics', Learning Transformations: FACE 2003 conference. University of Stirling, Stirling 2-4 July. Available at: http://www.face.stir.ac.uk/documents/Paper015McLinden.pdf (Accessed: 23 December 2011). 
Mercer, J. (2007) 'The challenges of insider research in educational institutions: wielding a double-edged sword and resolving delicate dilemmas', Oxford Review of Education, 33(1), pp. 1-17.

Moon, J. (2004) A handbook of reflective and experiential learning: theory and practice. London: Routledge Falmer.

Osterman, K.F. (2000) 'Students' need for belonging in the school community', Review of Educational Research, 70(3), pp. 323-367.

Parkes, S. (2012) 'Giving students a 'HEADstart'; discussing the impact of a pre-induction course on student experience, and their progression within higher education after the first two years of undergraduate study', What Works? Student Retention and Success Conference 2012. University of York, York 28-29 March. Available at: https://newman.academia.edu/sarahparkes (Accessed: 26 June 2014).

Parkes, S., Cousins, H. and Blackwell-Young, J. (2013) 'Senior Academic Support Tutors: fostering student engagement through supporting academic development', in Clark, R., Andrews, J., Thomas, L. and Aggarwal, R. (eds.) Compendium of effective practice in higher education: Volume 2. York: Higher Education Academy, pp. 169173 [Online]. Available at:

http://www.heacademy.ac.uk/assets/documents/retention/Compendium 2 rc ja Fi nal.pdf (Accessed: 19 November 2013).

Quinn, J. (2004) 'Understanding working-class 'drop-out' from higher education through a sociocultural lens: cultural narratives and local contexts', International Studies in Sociology of Education, 14(1), pp. 57-74.

Quinn, J., Thomas, L., Slack, K., Casey, L., Thexton, W. and Noble, J. (2005) From life crisis to lifelong learning: rethinking working-class 'drop out' from higher education. York: Joseph Rowntree Foundation.

Siemens, G. (2004) 'Connectivism: a learning theory for the digital age', elearnspace: everything elearning. Available from: http://www.elearnspace.org/Articles/connectivism.htm (Accessed: 3 June 2009). 
Thomas, L. (2002) 'Student retention in higher education: the role of institutional habitus', Journal of Educational Policy, 17(4), pp. 423-32.

Thomas, L. (2011) 'Do pre-entry interventions such as 'Aimhigher' impact on student retention and success? A review of the literature', Higher Education Quarterly, 65(3), pp. 230-250.

Thomas, L. (2012) Building student engagement and belonging in higher education at a time of change: a summary of findings and recommendations from the What Works? Student Retention \& Success programme, London: Paul Hamlyn Foundation.

Thomas, L. and Quinn, J. (2006) First generation entry into higher education. Milton Keynes: Open University Press.

Thomas, L. and Jamieson-Ball, C. (eds.) (2011) Engaging students to improve student retention and success in higher education in Wales. York: Higher Education Academy [Online]. Available at:

http://www.heacademy.ac.uk/resources/detail/inclusion/Retention/EngagingStudent stolmrpoveRetentioninWales English (Accessed: 14 June 2011).

Thomas, L. and May, H. (2011) 'Student engagement to improve retention and success model', in Thomas, L. and Jamieson-Ball, C. (eds.) Engaging students to improve student retention and success in higher education in Wales. York: Higher Education Academy, pp. 11-21 [Online]. Available at:

http://www.heacademy.ac.uk/resources/detail/inclusion/Retention/EngagingStudent stolmrpoveRetentioninWales English (Accessed: 14 June 2011).

Tinto, V. (2006) 'Research and practice of student retention: what next?', Journal of college student retention, 8(1), pp. 1-19 [Online]. Available at: http://edit.uaa.alaska.edu/governance/facultysenate/upload/JCSR Tinto 200607 Retention.pdf (Accessed: 11 December 2011).

Trochim, W. (2006) 'Positivism and Post-Positivism', Research Methods Knowledge Base [online]. Available at: 
http://www.socialresearchmethods.net/kb/positvsm.php (accessed 19 December 2009).

Vaill, P.B. (1996) Learning as a way of being. San Francisco, CA: Jossey-Blass Inc.

Walker, L. (1999) 'Longitudinal study of drop-out and continuing students who attended the Pre-University Summer School at the University of Glasgow', International Journal of Lifelong Education, 18(3), pp. 217-233.

Walker, L., Mathew, B. and Black, F. (2004) 'Widening access and student noncompletion: an inevitable link? Evaluating the effects of the Top-Up Programme on student completion', International Journal of Lifelong Education, 23(1), pp. 43-59.

White, D. and Le Cornu, A. (2011) 'Visitors and residents: a new typology for online engagement', First Monday, 16(9) [Online]. Available at: http://firstmonday.org/ojs/index.php/fm/article/view/3171/3049 (Accessed: 20 February 2012).

Yorke, M. and Thomas, L. (2003) 'Improving the retention of students from lower socioeconomic groups', Journal of Higher Education Policy and Management, 25(1), pp. 63-75.

Yorke, M. and Longden, B. (2008) The first-year experience of higher education in the UK: final report. York: The Higher Education Academy.

\section{Author details}

Sarah Parkes is a Tutor for Transition and Retention at Newman University, Birmingham. Sarah's principal interests lie in the factors affecting student retention, progression and success in a widening participation context. As well as supporting student themselves, this includes notions of institutional transformation that develops staff capacity to enable student success, rather than looking for increased homogeneity within the student body. 